\title{
Breves notas sobre a ética a partir de Adília Lopes
}

\author{
Pedro Meneses \\ Universidad de los Andes (Bogotá) / CEHUM
}

Resumo: Este artigo pretende demonstrar como, nos poemas de Adília Lopes, a maldade tem impacto psicológico e interpessoal em episódios em que muitas vezes se estabelece um pacto autobiográfico. A maldade manifesta-se como vaidade, hipocrisia social ou vontade de poder, também denunciadas no mundo da arte. Na poesia de Adília, a pessoa sempre se sobrepôs à grandeza pressuposta na noção de autor. A sua obra desconstrói lugares comuns da linguagem por forma a atestar a arrogância da ideologia. Consubstancia uma ética e um desejo (segundo o Roland Barthes final) que tenta vencer o desencanto: existe a possibilidade de se ser "mulher-a-dias", de viver cada dia entregue a textos, leituras e ao exigente ofício da bondade. Talvez Adília Lopes seja a legenda mais acertada para as suas fotografias de infância e juventude, o nome de guerra com que a autora civil vive a sua vocação.

Palavras-chave: desencanto, ética, ideologia, ironia, mal

Abstract: The article aims to demonstrate that, in Adília Lopes poems, evil has a psychological and interpersonal impact in episodes in which it is established an autobiographical pact. Evil manifests itself as vanity, social hypocrisy or will to power, also denounced in the art-world. In Adília's poetry, the person has always superimposed itself upon the grandeur presupposed in the notion of author. Her poetic work deconstructs linguistic commonplaces in order to show the arrogance of ideology. It embodies an increasingly consistent ethic and desire (according to the final Roland Barthes) that try to overcome disenchantment: there is a possibility of to be a "mulher-a-dias", who lives every day dedicated to texts, to readings and to the demanding task of kindness. Perhaps Adília Lopes is the most accurate caption for her childhood and youth photographs, the war name with which the civil author lives her vocation.

Keywords: disenchantment, ethics, evil, ideology, irony 
Mas António também se fez menor, para se pegar mais a Deus.

O bom gosto é como as trufas. Os porcos dão com elas nem que estejam a cem metros de distância, debaixo das folhas.

Agustina Bessa-Luís

Na obra de Adília Lopes, a pessoa sobrepõe-se à figura do autor, como o destacaram os críticos Américo Lindeza Diogo (1998; 2000) e Osvaldo Silvestre (2001) num tempo em que a defesa desta poesia no mundo académico adquiria contornos de escândalo. O lance teórico de desconstrução da impessoalidade poética é, em Adília, menos um fim em si mesmo do que necessidade subjetiva de expressão de sofrimento não só psicológico e individual como social e político, isto é, representativo da condição feminina na modernidade avançada. Neste artigo, interessa-nos indagar como, sobretudo nos últimos livros de Adília Lopes, se configuram uma ética, escolhas sobre como viver, que, com a ironia, contrabalançam o desencanto.

\section{Construção de uma ética}

A poesia de Adília Lopes contorna a despersonalização textual e sublinha que a aura e a transcendência criadas pela maioria dos poetas em torno de si mesmos são vaidade e vazio cuja única virtude é nunca expirar. A pessoa adiliana é o contrário do poeta como ser mais alto cantado por Florbela Espanca, apesar de se expressar, em ambas as poetisas, com nuances, "um eu desinibidamente sentimental e confessional" (Klobucka 2009: 320). Adília Lopes é nome que estabelece distância que torna possível pensar e construir a vida e a pessoa sem que textualmente seja autorizada uma identificação inequívoca entre autor poético e autor civil. Escreve poesia em deflação, de modo lúcido, sem cedências ao bom gosto estético, moral ou sentimental, nem, por consequência, à enunciação de embriagantes humanismos. Poesia que denuncia a falsa grandiloquência de outras poesias e existências, 
não propondo como alternativa a heroicização da sua tristeza. A honestidade no seu autorretrato depende da revelação das suas inconsistências.

Estar em Casa é uma obra que completa uma trilogia de afetos e ligações (a manhã, luz, criação, espaço da infância na memória; a pequena canção do bandolim; a casa, ${ }^{1}$ onde mais livremente se pode ser quem se é): "E a literatura continua a ser para mim uma coisa muito séria. Literatura não é aldrabar, não é seduzir, seduzir é aldrabar" (Lopes 2018: 42). Aldrabice pois o palavreado e o espampanante criam uma mentira, literária e sobretudo ética: a autossacralização, aliás talvez o modo mais comum de um poeta se tornar vendível. Releiamos Sete rios entre campos (1999): “Dido no Inferno / cumprimenta Eneias / é preciso ter boas maneiras / em toda a parte / especialmente/ em questões de Arte" (Lopes 2014: 350). ${ }^{2}$ Crítica também dirigida a uma burguesia semieducada, que muitas vezes é apresentada como elite cultural (com analogias com a mundividência de um Pasolini) por sua postura de permanente zombar, queixa narcísica e indignação difusa; em síntese, calúnia da vida. Lê-se em "A inteligente gente", texto em prosa de Bandolim que revela possíveis motivos para a relutância do milieu literário em aceitar Adília no seu seio: "A inteligente gente é zombeteira. Sei isto desde que tenho consciência do mundo, desde os anos 60 . Não vi outra coisa. Acho isto muito estúpido e de muito mau gosto. É uma moda. Uma má moda. Às vezes até são boas pessoas" (Lopes 2016: 154). ${ }^{3}$ Um mau hábito perspetivado como expressão do bom gosto pela tribo da "inteligente gente". Note-se que para além do efeito pop conseguido pela rima interna e em eco está uma observação sensível e exata sobre a condição humana.

Exemplifica tal lucidez um poema sobre uma conferência de Hans Magnus Enzensberger (Lopes 2000: 157) no qual é denunciada a contradição entre a autossatisfação intelectual do orador e o pessimismo com que discorre sobre a circunstância do mundo:

\author{
Hans Magnus Enzensberger \\ na Casa Pessoa \\ mostrou-se \\ muito pessimista \\ em relação \\ ao mundo \\ mas muito contente
}


consigo mesmo

A propósito, refira-se que, em Assim falava Zaratustra, Nietzsche (2010: 264) afirma que a vaidade pode ter duas origens: o poder ou o saber. Tanto o estatuto social como a erudição podem provocar a altivez conducente ao rebaixamento dos demais. Os poemas de Adília dedicam-se com extremas sensibilidade e atenção a revelar como se exibe, de modo presunçoso e absurdo, poder social ou erudição. Na parte da denúncia dirigida a intelectuais, está subjacente a ideia de que inteligência e cultura deveriam ser bem mais do que um acervo de conhecimentos debitado por vanglória ou segundo fins práticos de poder. Deveriam estar ao serviço da constituição de uma ética que fosse não só disponibilidade para aperfeiçoar-se e aprender continuamente através da escuta do outro, mas também abandono ascético do supérfluo.

A despoetização que nos primeiros livros era feita de modo mais sarcástico e em poemas romanceados extensos, torna-se nas obras recentes concisa, axiomática, em textos que muitas vezes são notações do quotidiano, haikus, desconstruções de lugares comuns, comentários resumidos a outros poemas, por vezes cometendo a 'heresia' de sintetizar o canónico, ${ }^{4}$ tornando-o piada ou slogan. Tais construções textuais parecem ter sido influenciadas por textos do Roland Barthes final.

Incidentes, obra em que Adília admira a coragem de se ter evitado o bom gosto parisiense (Lopes 2016: 177), é constituída por notações fragmentadas, íntimas e descontextualizadas de cariz diarístico que não estabelecem entre si uma continuidade de sentido. São o resultado de "todo cuanto cae, como una hoja" (Barthes 2009: 184). ${ }^{5}$ Roland Barthes por Roland Barthes também parece ter sido uma influência para a Adília desta trilogia, pois nele Barthes inquere conceitos literário-filosóficos a partir de exercícios de memória e através da reflexão sobre a experiência do corpo, ao mesmo tempo que legenda alguns dos seus retratos e fotografias de infância e juventude. Falta acrescentar $O$ Prazer do Texto, exercício teórico, literário e ético em que Barthes abandona definitivamente a vontade de sistema e constitui um plano de imanência em que defende a leitura do que dá prazer numa escrita e num pensamento que avançam seguindo os fluxos do desejo. Do nosso ponto de vista, os últimos livros de Adília Lopes são uma tentativa árdua de constituição desse plano, estabelecendo-se como intervalos em que se suspende um dissídio com a existência. Esse dissídio (hipótese: toda a poesia é contestação metafísica da 
realidade) manifesta-se em certos poemas com uma acentuação lúcida e melancólica do tópico da predação sexual, que socialmente recebe o nome de bom gosto, sucesso, ou kitsch. Fodas são enunciadas como bodas, o bonito oculta o luxo de viver e o interesse financeiro; tanto o jogo fonético entre a fricativa e a oclusiva como a falsa rima denunciam a hipocrisia social. ${ }^{6}$ Em sentido inverso, valoriza mais o desejo de viver, o prazer de escrever e ler, de proteger as suas afeções e ligações, a alegria. Lê-se em Estar em Casa: "O prazer do texto sim / o frete do texto não" (Lopes 2018: 33). Tal valorização também é formulada no imediatamente anterior, com o qual dialoga: "Ou isto ou aquilo / ou isto ou aquilo / isto e aquilo" (idem: 19). Um poema curto sobre a insistente lógica social da exclusão, a que é contraposta uma lógica inclusiva, de conexão, na qual Gilles Deleuze e Claire Parnet (2004: 75) encontravam um potencial criativo. Essa lógica inclusiva está presente na citação, na alusão, no resumo; em suma, em todo o reportório paródico de Adília que configura gestos que vão desde a homenagem (o mais frequente) ao rebaixamento, os quais não autorizam distinção de valor entre alta e baixa cultura e denunciam os mecanismos de poder e afetação oriundos da denominada alta cultura.

Do nosso ponto de vista, os textos breves mais recentes de Adília Lopes evidenciam um devir-menor com dimensão ética (com origem cristã, mas não só), sintomático desde logo na economia de meios da sua poesia, assim como na referida índole paródica, isto é, na admiração humilde e culta pela obra de outros, pelas influências, atitude que não se coaduna com a apologética do génio romântico. Esta ética condensa-se sabiamente num dístico de Apanhar Ar (2010): "Na vida e no poema / dar menos um passo" (Lopes 2014: 652). Versos que expressam a intenção de um devir cada vez mais sóbrio, que afirmam dispensar na existência e na poesia o adorno, a presunção e a épica da sua melancolia. Este despojamento formal é uma opção ética que veicula por si mesma uma arte de viver. Para Deleuze e Parnet (2004: 41), o devir é a sobriedade que permite avançar numa ação, sem passado nem futuro, sempre no meio, permitindo agenciamentos entusiasmados: "No devir, trata-se antes de involuir: não é nem regressar, nem progredir. Devir, é devir cada vez mais sóbrio, cada vez mais simples, devir cada vez mais deserto, e por isso mesmo povoado".

Na obra de Adília Lopes não se sente uma angústia imobilizadora da influência. No ensaio sobre a obra de Foucault, Deleuze discute um 'poder de afetar', clássico, poder 
emissor, de instigação, de determinação e, no limite, como no caso de instâncias de poder como o Estado, de normalização (Deleuze 2015: 99). Descreve igualmente um outro poder, 'o de ser afetado', o de, conscientemente, ser possível a cada um tornar-se frágil diante de quem sabe, deste modo afirmando-se disponível para receber, ser influenciado, aprender, mudar. Este poder deriva de uma faculdade de interpretação e de uma sensibilidade agudas. ${ }^{7}$ É neste sentido que entendemos a influência de vários autores (Ruy Belo, Sophia de Mello Breyner, Condessa de Ségur, Rimbaud, Apollinaire e tantos outros) na obra adiliana: uma disponibilidade para ouvir, ler, estar atento, continuar a pensar. Esta disponibilidade é, pois, um antídoto para a indiferença e para o tédio; é ativa, permite o movimento. É do espanto pela descoberta de ideias ou estilos interessantes, no momento da leitura, que nasce o entusiasmo criador.

Os versos adilianos pensam sobre a existência de um modo irónico, pois, neste registo, podem sabotar a grandiloquência e moderar a vertigem devoradora da maldade. Muitas vezes, o poema parece reportar-se a um episódio autobiográfico, ponto de partida para uma reflexão cujo conteúdo depressivo é contido pela ironia. Em "Os papelotes" de $O$ Decote da Dama de Espadas (Romances) (1988), é evocada uma ansiosa e feroz vontade de ser bela que elide a possibilidade de o sujeito poético se tornar naquilo que é:

Os papelotes

Nunca choraremos bastante
termos querido ser belas
à viva força
eu quis ser bela
e julguei que para ser bela
bastava usar canudos
pedi para me fazerem canudos
com um ferro de frisar e papelotes
puxaram-me muito pelos cabelos
eu gritei
disseram-me para ser bela
é preciso sofrer
depois o cabelo queimou-se




\author{
não voltou a crescer \\ tive de passar a andar com uma peruca \\ para ser bela é preciso sofrer \\ mas sofrer não nos faz forçosamente belas \\ um sofrimento não implica como consequência \\ uma recompensa \\ uma dor de dentes pode comover a nossa mãe \\ que para nos consolar sem saber de quê \\ nos dá um rebuçado \\ mas o rebuçado ainda nos faz doer mais os dentes \\ a consequência de um sofrimento \\ pode ser outro sofrimento \\ a causa é posterior ao efeito \\ o motivo do sofrimento é uma das consequências \\ do sofrimento \\ os papelotes são uma consequência da peruca. \\ (Lopes 2014: 145-146)
}

Porque após o sofrimento se pode seguir sofrimento, e não algo bom, fica autorizada a inversão de causa e efeito; logo, é logicamente aceitável que os papelotes sejam consequência da peruca. Para além da graça final, que suaviza a brutalidade do episódio e da lucidez com que foi interpretado, note-se como o poema elucida quanto à frequente ingenuidade que é esperar o bom e o belo depois do sofrimento, como se, ao contrário da lógica compensatória a que o mundo estaria supostamente obrigado, não pudesse sobrevir sofrimento ao sofrimento, nem fosse possível conceber o sofrimento senão, narcisicamente, como injusto. Como tantas vezes acontece, a insuprível necessidade de consolo é uma armadilha existencial que pode ter por efeito mais sofrimento. Registe-se outrossim a denúncia intrínseca a esta lógica social, à doxa: és feia porque não sofres o suficiente. Recai, desta forma, uma acusação social sobre quem não corresponde aos padrões de beleza: a fealdade é culpa própria e ausência de autossacrifício.

Neste texto, avulta ainda a ideia de que embelezar é endireitar com violência o que está torto, denunciando-se a censura tribal que recai sobre o desvio de comportamento ou estético. Lê-se no fragmento "Nariz" de Bandolim: "A minha avó materna não gostava do 
meu nariz. Quando se cruzava comigo no corredor, dizia-me: "nariz não é feição»" (Lopes 2016: 45). O gracejo, que é citação de Amália Rodrigues, agrava a acusação recorrente da avó. A marginalidade poética de Adília parece ter-se constituído longinquamente na exposição dura a um quotidiano asfixiante.

"Nariz" retoma um topos da poesia adiliana de acordo com o qual uma aproximação angustiada e dominadora da realidade pode provocar mais desordem e violência do que ordem. A procura da ordem, que nasce de uma melancolia irremível, de angústia metafísica, pode ser mais violenta que a desordem, como o explica sinteticamente o poema "Anti-Nazi" de César a César (2003):

\author{
A limpeza \\ pode ser \\ pior \\ que a porcaria \\ A ordem \\ pode ser \\ a maior \\ desordem \\ (Lopes 2014: 505)
}

Dois axiomas enunciados de modo "ironicamente simétrico" (Evangelista 2011: 103) que destacam que a tentativa de estabelecer uma ordem racional pode engendrar os piores monstros. O nazismo tinha por intenção restabelecer uma suposta ordem prévia à Primeira Guerra Mundial. Tal processo na intenção utópico terminou miseravelmente e saldou-se por uma tanato-política executada por uma racionalidade e uma legalidade extremas e consubstanciada nas fábricas de morte. Zygmunt Bauman explicou, em Modernidad y Holocausto (2008), como as fábricas de morte foram um culminar perverso do projeto iluminista e estavam sob a alçada do Ministério da Economia nazi, porque deveria ser um processo executado com o máximo de eficiência. Ressalve-se que a racionalidade técnica permite que o exercício da maldade seja mais eficaz, mas também permite que o exercício da bondade o seja. Trata-se de um poema lúcido sobre o qual poderíamos trazer ainda à 
colação Paul Valéry (1993: 47) que afirmou que "dois perigos ameaçam constantemente o mundo: a ordem e a desordem". Não é que Adília considere algo ingénua ou até romanticamente que os efeitos da desordem são sempre bons, porém acentua o potencial maligno e desesperado inscrito na tentativa de estabelecer uma ordem.

Talvez possamos resumir a ética de Adília através deste poema de Bandolim, um jogo linguístico cuja base é a mudança significativa de sentido possibilitada por traços mínimos fonéticos: "São tristes / os trastes" (Lopes 2016: 130). A predação social, que define os trastes (os que usam a sua força para tirar algum tipo de vantagem sobre os outros), manifesta e exacerba uma relação angustiada com a existência, em contraste com a alegria de quem faz algo ético com os dias, com a vida, numa tentativa ascética de transcender o quotidiano: "Escreve poemas, pequena / escreve poemas / e come chocolates / e que os poemas / sejam como chocolates" (Lopes 2018: 74). Escrever, ler, preenchem o dia da mulher-a-dias, conhecida metáfora adiliana que deu origem a um livro e torna vívida uma metáfora morta, transformada em metáfora da existência: "Vivo / dia a dia / sou / uma mulher-a-dias // Dia a dia / perto porto parto / da eternidade" (Lopes 2014: 597). Como a mulher-a-dias vive no limite da subsistência de cada trabalho breve, Adília escreve e lê em cada dia, aceitando esta medida de tempo como a sua, a de mortal. Neste poema subvertese o lugar-comum, o da multidão, criando-se um lugar individual, especial. Descobrem-se novas ligações entre as palavras. É a linguagem que localiza o humano, pois não se consegue chegar a um lugar insólito com frases miseráveis, se forem frequentados os lugares da multidão (Tavares 2004: 106). Sublinha-se nestes versos a sua condição de poetisa não só financeiramente precária como dedicada, dentro do tempo, dos dias, consumidos com escrita e leitura. Enquanto escreve, Adília está na eternidade, sem a angústia de assistir exteriormente à passagem do tempo.

Neste poema recorre-se ao paradoxo, figura de estilo que, explica Barthes (1987: 71), etimologicamente significa tanto "ao lado da doxa" como "contra a doxa", exprime sentidos de aproximação e oposição. A poesia é performance que subverte a linguagem comunicativa, a doxa, o conjunto de valores dominante, ou seja, “a Opinião pública, o Espírito maioritário, o Consenso pequeno-burguês, a Voz do Natural, a Violência do Preconceito" (Barthes 2009: 58). Estes valores estão relacionados com a defesa de um 
individualismo predatório segundo o qual cada um deve lutar por uma melhor posição no mundo, com mais dinheiro, mais beleza, em contextos cada vez mais refinados de socialização, tendo para isso que rebaixar ou tirar proveito dos outros. Barthes considera que os discursos, os saberes e os jogos de forças no campo da cultura levam a imposições arrogantes de uns sobre outros, sintetizando tal ideia numa imagem sugestiva: "A arrogância circula como um vinho forte entre os convivas do texto" (ibidem). Por isso o crítico francês considera redundante a expressão 'ideologia dominante', porquanto 'ideologia' significa desde logo 'ideia que domina' (idem: 59). Propõe, em alternativa, a ideia de "ideologia arrogante" (ibidem). Os paradoxos adilianos são, portanto, não apenas modos de desconstruir a ideologia, mas também de combater a arrogância e a fome de destino que têm por finalidade decisiva a constituição de uma arte de viver. Sabotar a doxa é a única hipótese para o movimento ético e para o pensamento: “A Doxa é a opinião corrente, o sentido repetido, como se nada fosse. É a Medusa: petrifica aqueles que a vêem" (Barthes 2009: 150; itálicos do autor). A poesia de Adília expõe e confronta um eu desnudado pelo enlouquecimento ético e moral da normalidade e da ideologia. Como uma delicada máquina de guerra, contrapõe silêncio zen e ironia ao palavreado sério e jactante próprio da ideologia, da informação. Como o assumiu Roland Barthes, Adília poderia dizer: "Tenho uma doença: vejo a linguagem" (idem: 197; itálicos do autor).

\section{Desencanto}

A gente se negava corromper-se aos bons costumes Manoel de Barros

Esta arte de viver, que passa por uma escrita despojada e paradoxal, pela defesa de hábitos de natureza ética como ler, escrever, muitas vezes no café, enuncia a possibilidade de afastamento do meio humano onde o poder se manifesta radicalmente. ${ }^{8}$ Este posicionamento implica, de certo modo, desencanto - a consciência de que tudo falta e de que tudo é demasiado, sendo, por isso, difícil continuar. No desencanto desconstrói-se o lugar-comum segundo o qual a existência deve ser publicitada (Theodor Adorno apud Diogo 2000: 478). Todavia, a dimensão da denúncia sucumbe à violência do combate. 
Logo no primeiro livro da poetisa, Um jogo bastante perigoso (1985), está presente uma lucidez auto-devoradora:

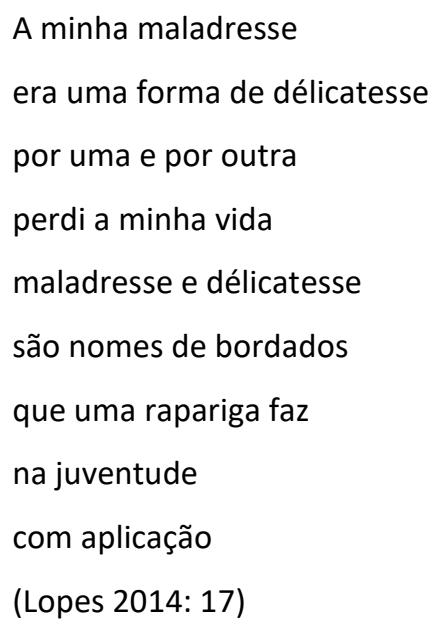

Nesta extraordinária leitura do célebre poema de Rimbaud, "Chanson de la plus haute tour", explica-se como a imperícia para viver resulta de um excessivo pudor, que, de outro ângulo, é respeito pelo outro, recusa em impor-Ihe outra vontade. Tanto por falta de jeito como por delicadeza, Adília reconhece, terrivelmente, ter perdido a sua vida. Uma excessiva interioridade e uma dedicação extrema em anular-se são efeitos porventura de uma educação das raparigas para atividades finas como bordar, que potencialmente as despreparam para uma existência em que alguma brutalidade é necessária para avançar e fazer. No lugar dos ócios rimbaldianos da juventude estão os bordados, duas formas de coação, dois instigadores de inércia.

Talvez o lugar em que a voz da ideologia mais se faça sentir seja o consultório do psicanalista, em vários poemas alvo de escárnio. Em Café e Caracol (2011), lê-se: "Um psicanalista disse-me: "A vida é luta. Perca a vergonha.» Eu não quero perder a delicadeza" (Lopes 2014: 665). A resistência de Adília às injunções do psicanalista - que visam corrigir o que está torto - significa que o respeito pelo outro é o mais importante. A poetisa desmascara a prepotência subjacente à normalização imposta pelo psicanalista. Note-se, contudo, o custo psicológico desta opção ética e ainda a renúncia em fazer da derrota um feito heroico com efeitos poéticos. 
Em alguns textos, Adília Lopes parece espantar-se com a bondade, pressupondo-se que a maldade define, essencialmente, o mundo, coberto pela mentira da beleza e dos sentimentos açucarados: "O mundo é uma casa de passe / com as paredes salpicadas / de geleia de framboesa" (Lopes 2014: 340). Neste território textual, assiste-se muitas vezes a uma luta contra o desencanto. No último livro da autora, é narrado um episódio forte, intitulado "Praia":

Tinha 30 anos. Num Santo António ou num dia de Camões fui sozinha à praia de S. Pedro do Estoril. Havia bastante gente mas não muita. Perto de mim estava um pai e um filho, o pai era pela minha idade. Nunca me ponho a ouvir conversas, não tenho cabeça para isso. Mas era inevitável ouvir o que diziam. Percebi que o rapaz devia estar divorciado e que passava pouco tempo com o filho. 0 filho tinha uns 10 anos. Tinham dificuldade em conversar. A minha vida era triste mas vi que havia pessoas com problemas muito diferentes dos meus que também tinham uma vida triste. Fiquei contente com uma coisa: pareceram-me boas pessoas. Quando fui tomar banho, pedi-lhes para guardarem o meu saco e a minha roupa, as minhas coisas. Sou míope, quando vou tomar banho deixo os óculos na areia, no saco. Já tomei banho de óculos e o mar arrancou-me os óculos da cara e eu nunca mais vi os óculos. O problema é encontrar o lugar na areia depois de tomar banho. Sem os óculos, vejo pouco. Mas nunca me perdi na praia. Nesse feriado Santo António ou Camões fiquei contente por ter podido confiar em desconhecidos. Nem todas as pessoas são más. Mas eu acho que as pessoas são más e que não vale a pena falar disso. (Lopes 2018: 63)

Destaque-se neste episódio comovente o humor, suavizando o desencanto sem o anular. Um episódio que parece ter sido vivido em circunstâncias difíceis. O que distingue Adília de autoras como Sylvia Plath é o humor, existencialmente imprescindível, ainda que não salve necessariamente. Ambas expõem a mesma fragilidade existencial: "It is a terrible thing / To be so open: it is as if my heart / Put on a face and walked into the world" (Plath 2013: 78). Em "Praia", o desencanto não cessa, é aliás com ele que o episódio termina, tendo Adília sido salva pela bondade de desconhecidos. Encontrar apenas bondade no mundo, talvez a expectativa mais perigosa, adverte Nietzsche (2010: 156). Tal expectativa associada a uma atenção lúcida e sensível à maldade pode tornar-se obstáculo intransponível à alegria.

Mais do que um pseudónimo, Adília Lopes é o nome de guerra que Maria José da Silva Viana Fidalgo de Oliveira encontrou para suportar o peso do mundo e do passado e 
poder ir ao encontro de quem é: "Escrevo escrevo escrevo escrevo almadamente. Almadamente é o contrário de desalmadamente. E é Almada Negreiros, Nome de guerra" (Lopes 2016: 129). Adília Lopes como o nome da sua vocação de escritora, nome de uma individualidade que se afirma entre as coações do século e os conselhos dos vencedores. ${ }^{9}$ Escrever é esquecimento da humanidade, da violência provocada pelo açúcar: "Barthes escreveu já não sei onde cito de cor: o açúcar é violento. Acho que tem razão" (Lopes 2015: 94). A obra de Adília mostra a perversidade da embriaguez humanista e também o modo como, em nome da humanidade, se esquece a vocação. As fotografias antigas são legendadas com o nome Adília devido ao sentido que ele condensa: hábitos de leitura e escrita, fluxos por onde passa o desejo e a vida.

\section{NOTAS}

\footnotetext{
${ }^{1}$ Acrescente-se ainda o café, como cantado neste breve haiku de Apanhar ar: "Café / lugar que é rua / e casa" (Lopes 2014: 654). Espaço protegido onde se realiza o duro combate pela alegria da escrita e da leitura, reconhece a autora em entrevista:

Sim, tenho hábitos rígidos de ir ao café a tantas horas, de fazer certas coisas sempre às mesmas horas, sempre da mesma maneira, e depois, como não tenho uma vida muito fácil... o que consigo fazer é com esforço e então nem sempre consigo fazer o que quero, não é?, o que gostaria de fazer, e assim nem sempre leio os livros todos que queria ler, nem sempre escrevo o que queria escrever, é uma luta, é o que consigo fazer. (Lopes 2017)
}

No café várias pessoas se cruzam, é um lugar humilde, bem diferente do pensamento: "Ele viveu sempre no meio dos seus pensamentos. Senhor absoluto no reino de papel! Isso dá excedentes enormes de autoconfiança e de arbítrio. Acotovelarmo-nos contra pessoas limita e torna-nos humildes" (Robert Musil apud Tavares 2004: 109).

${ }^{2}$ Em entrevista, observa a autora após Ihe ter sido feita uma pergunta sobre o seu interesse pelo meio literário: “Não, também não tenho. Tenho uma ideia que é um meio de intrigas e assim, como todos os meios 
profissionais, como todos os meios humanos, e não só profissionais, tudo. E isso não me interessa" (Lopes 2017).

${ }^{3}$ Leia-se outro episódio da mesma natureza, em Estar em Casa: "Uma médica rica fazia troça dos pacientes iletrados pobres porque lhe perguntavam, quando ela se esquecia de Ihes medir a tensão, «Então hoje a senhora doutora não me mede a atenção?»" (Lopes 2018: 27).

${ }^{4}$ No poema “Os dias vão-se/ eu não" (Lopes 2014: 369), o trágico “Le pont Mirabeau” de Apollinaire é reduzido a uma fórmula irónica e icónica (cf. Diogo 2000).

5 Livro publicado postumamente dividido em duas partes. A primeira, "Incidentes", regista notações quotidianas, efabulações e reflexões curtas durante viagens por Marrocos em 1968 e 1969. A segunda, "Soirées de Paris", são de natureza diarística, referentes a agosto e setembro de 1979, e desnudam o autor na sua fragilidade. É o caso deste exemplo em que o autor se reconhece enganado mas, apesar de tudo, satisfeito pela expectativa do desejo erótico proporcionada por um gigolô: "Siempre esa dificultad de trabajar a la tarde. Salí a eso de las seis y media, a la aventura; divisé en la calle de Rennes a un gigoló nuevo, pelo sobre la cara, aro delgado en la oreja; como la calle B. Palissy estaba totalmente desierta, conversamos; él se llamaba François; pero el hotel estaba lleno; le di dinero, me juró estar en la cita una hora más tarde, y por supuesto no estaba. Me pregunté si realmente me había equivocado (todo el mundo exclamaría: dar plata de antemano a un gigoló!), y me dije que, puesto que en el fondo no le tenía tantas ganas (ni siquiera tenía ganas de acostarme), el resultado era el mismo: acostado o no, a las ocho me habría encontrado en el mismo punto de mi vida; y, como el simple contacto de los ojos, de la palabra, me erotiza, es ese goce el que pagué" (Barthes 2016: 70).

6 "As fodas que sempre se querem bodas, os meus contemporâneos são bem intencionados", lê-se na nota de abertura a O regresso de Chamilly (Lopes 2014: 437).

${ }^{7}$ Um princípio da escrita de Gonçalo M. Tavares que consideramos comum à poesia de Adília Lopes: "Claro, para mim, isto: não a angústia da influência, mas sim a angústia da não influência: ver, ouvir, ler e: nada, nenhuma influência" (Tavares 2004: 91). Mais do que uma técnica de oficina, está em causa um posicionamento individual em relação ao mundo: "A força para ser fraco o suficiente para receber a força dos outros" (ibidem).

${ }^{8}$ Uma solidão fértil, todavia, como se lê em Irmã Barata, Irmã Batata: "O deserto está perto. Sempre. Mas o deserto é fértil" (Lopes 2014: 416).

${ }^{9}$ Escreve o lúcido, sensível e essencial Barthes (2009: 58), num fragmento com o título "A arrogância": "Ele não gosta de discursos de vitória. Suportando mal a humilhação de quem quer que seja, logo que uma vitória se desenha algures, fica com vontade de se mudar para outro lado (se fosse deus, havia de inverter sem cessar as vitórias - o que de resto Deus faz!)". 


\section{Bibliografia}

Barthes, Roland (1987), O Prazer do Texto, tradução de J. Guinsburg, São Paulo, Perspectiva.

-- (2009), Roland Barthes por Roland Barthes, tradução de Jorge Constante Pereira \& Isabel Gonçalves, Lisboa, Edições 70.

-- (2016), Incidentes, tradução de Víctor Goldstein, Buenos Aires, La Marca Editora.

Bauman, Zygmunt (2008), Modernidad y Holocausto, tradução de Ana Mendoza \& Francisco Ochoa Michelena, Madrid, Sequitur.

Deleuze, Gilles (2015), Foucault, tradução de Pedro Elói Duarte, Lisboa, Edições 70.

-- / Claire Parnet (2004), Diálogos, tradução de José Gabriel Cunha, Lisboa, Relógio d'Água.

Diogo, Américo Lindeza (1998), "Poemas com Pessoa", in Lopes, Adília, O Poeta de Pondichéry seguido de Maria Cristina Martins, Braga-Coimbra, Angelus Novus, 67-88.

-- (2000), “Posfácio Adília Lopes Obra”, in Lopes, Adília, Obra, Mariposa Azual, Lisboa, 473494.

Evangelista, Lúcia (2011), Vida em Comum. A Poética de Adília Lopes, Dissertação de Mestrado em Estudos Literários, Culturais e Interartes, Faculdade de Letras, Universidade do Porto. Disponível em: https://repositorio-aberto.up.pt/bitstream/10216/57408/2/ TESEMESLUCIAEVANGELISTA000148379.pdf.

Klobucka, Anna (2009), O Formato mulher - a Emergência da Autoria Feminina na Poesia Portuguesa. Coimbra: Angelus Novus.

Lopes, Adília (2000), "Hans Magnus Enzensberger", in Zentral Park 2, Braga, Angelus Novus, 157.

-- (2014), Dobra, Lisboa, Assírio \& Alvim.

-- (2015), Manhã, Lisboa, Assírio \& Alvim.

-- (2016), Bandolim, Lisboa, Assírio \& Alvim. 
-- (2017), “Entrevista a Adília Lopes", <https://www.jogosflorais.com/entrevista/2018/ 1/26/entrevista-a-adlia- lopes?rq=Ad\%C3\%ADlia\%20Lopes> (último acesso em 01/09/2019). -- (2018), Estar em Casa, Lisboa, Assírio \& Alvim.

Nietzsche, Friedrich (2010), Assim Falava Zaratustra, tradução de Carlos Grifo Babo, Oeiras, Ad Astra et Ultra SA.

Plath, Sylvia (2013), Tres Mujeres, edição bilingue, tradução de María Ramos, Madrid, Nørdica Libros.

Silvestre, Osvaldo (2001), "Adília Lopes Espanca Florbela Espanca”, in Inimigo Rumor, 10, Rio de Janeiro, 7 Letras, 24-28.

Tavares, Gonçalo M. (2004), A perna esquerda de Paris seguido de Roland Barthes e Robert Musil, Lisboa, Relógio d’Água.

Valéry, Paul (1993), Estudios Filosóficos, tradução de Carmen Santos, Madrid, Visor.

Pedro Meneses é, desde janeiro de 2019, leitor da Cátedra Pessoa do Instituto Camões na Universidad de los Andes (Bogotá). É membro do Grupo de Investigação em Identidade(s) e Intermedialidade(s) do Centro de Estudos Humanísticos da Universidade do Minho (CEHUM). Tem publicado ensaios em revistas e livros nacionais e internacionais sobre a obra de Gonçalo M. Tavares. Concluiu um projeto de investigação individual financiado pela Fundação para a Ciência e Tecnologia de que resultou o ensaio Um valoroso lugar incerto. $A$ cartografia do humano em Uma viagem à Índia de Gonçalo M. Tavares (Editora Húmus, 2018). Lecionou Literatura e Língua Portuguesas na Universidade do Minho e na Escola Superior de Educação do Instituto Politécnico de Viana do Castelo. 